\title{
The association between childcare attendance and risk of childhood obesity in two year old children
}

\author{
A. E. McNamara ${ }^{1}$, K. L. Lindsay ${ }^{2}$, M. K. Horan $^{2}$, E. Gibney ${ }^{1}$ and F. M. McAuliffe ${ }^{2}$ \\ ${ }^{1}$ UCD Institute of Food and Health, University College Dublin, Belfield, Dublin 4, Republic of Ireland and ${ }^{2} U C D$ \\ Obstetrics and Gynaecology, School of Medicine and Medical Science, University College Dublin, National Maternity \\ Hospital, Dublin 2, Republic of Ireland
}

Rapid weight gain in the first two years of life has been shown to increase the risk of co-morbidities such as hypertension, sleep apnoea, hyperlipidaemia, asthma and type II diabetes mellitus in childhood as well as in adulthood ${ }^{(1)}$. The early-life environment, including adult-child relationships and childcare, have been shown play a role in shaping a child's nutritional and physical behaviours ${ }^{(2)}$. Previously published literature has demonstrated associations between various childcare settings and childhood overweight and obesity ${ }^{(3)}$, however, detailed anthropometric measurements have not been available. Furthermore, attendance in childcare has been associated with shorter breastfeeding duration and early introduction to solids ${ }^{(1)}$, which may impact on the child's weight status. The objective of this research was to examine anthropometric measures among children in and out of childcare in order to determine the association between childcare attendance and adiposity.

Children born to mothers who participated in the ROLO study ${ }^{(4)}$ (Randomised cOntrol trial of LOw GI diet in pregnancy) were recruited to a longitudinal follow-up study with data collection at two years of age. Details of childcare attendance were reported by mothers through questionnaires and the following anthropometric measurements were performed by the research dietitian at the two year follow-up appointment: Weight, height, abdominal circumference, mid-upper arm circumference and skinfold thickness measurements. Waist-hip ratio, waist-height ratio, body mass index centile, as per WHO child growth standards, and sum of skinfold thickness were calculated. Associations between childcare attendance and childhood anthropometric measures were analysed using ANCOVA, adjusting for mother's age and education level, as these factors differed at baseline.

\begin{tabular}{|c|c|c|c|c|c|}
\hline \multirow[b]{2}{*}{ Variables } & \multicolumn{2}{|c|}{$\begin{array}{l}\text { Attended } \\
\text { Childcare } \\
(N=136)\end{array}$} & \multicolumn{2}{|c|}{$\begin{array}{l}\text { Did Not } \\
\text { Attend } \\
\text { Childcare } \\
(N=129)\end{array}$} & \multirow[b]{2}{*}{$P$-value } \\
\hline & Mean & SD & Mean & SD & \\
\hline Abdominal Circumference $(\mathrm{cm})$ & $51 \cdot 14$ & $3 \cdot 51$ & $50 \cdot 02$ & $3 \cdot 24$ & $0 \cdot 029$ \\
\hline Mid-upper Arm Circumference (cm) & $16 \cdot 73$ & $1 \cdot 22$ & $16 \cdot 71$ & $0 \cdot 91$ & $0 \cdot 827$ \\
\hline Body Mass Index Centile & $59 \cdot 91$ & $49 \cdot 8$ & $62 \cdot 9$ & $50 \cdot 6$ & $0 \cdot 853$ \\
\hline Waist-Hip Ratio & $1 \cdot 03$ & $0 \cdot 06$ & $1 \cdot 01$ & $0 \cdot 06$ & $0 \cdot 100$ \\
\hline Waist-Height Ratio & 0.57 & $0 \cdot 04$ & $0 \cdot 56$ & $0 \cdot 04$ & 0.035 \\
\hline Sum of all Skinfolds $(\mathrm{cm})$ & $41 \cdot 79$ & $7 \cdot 27$ & $39 \cdot 2$ & $6 \cdot 81$ & $0 \cdot 012$ \\
\hline
\end{tabular}

Despite similar BMI centiles between the two groups of children, attendance in childcare was associated with greater childhood adiposity, particularly central adiposity, as indicated by a significantly higher abdominal circumference, waist-height ratio and sum of all skinfolds. Central adiposity is a risk factor for future metabolic disorders and obesity among these children. Implementation and close monitoring of healthy eating and physical activity policies in childcare settings may play an important role in attenuating childhood obesity rates.

1. Benjamin S, Rifas-Shiman S, Taveras E et al. (2009) Pediatrics 124, 555-562.

2. Maher E, Li G, Carter L et al. (2008) Pediatrics 122, 322-31.

3. Pearce A, Li L, Abbas J et al. (2010) Int J Obes 34, 1160-1168.

4. Walsh JM, McGowan CA, O'Mahony R et al. (2012) Br Med J 345, e5605. 